This item was submitted to Loughborough's Research Repository by the author.

Items in Figshare are protected by copyright, with all rights reserved, unless otherwise indicated.

\title{
Forging new frontiers in sustainable food manufacturing
}

\author{
PLEASE CITE THE PUBLISHED VERSION
}

http://dx.doi.org/10.1007/978-3-319-57078-5_2

\section{PUBLISHER}

(C) Springer

\section{VERSION}

AM (Accepted Manuscript)

\section{PUBLISHER STATEMENT}

This work is made available according to the conditions of the Creative Commons Attribution-NonCommercialNoDerivatives 4.0 International (CC BY-NC-ND 4.0) licence. Full details of this licence are available at: https://creativecommons.org/licenses/by-nc-nd/4.0/

\section{LICENCE}

CC BY-NC-ND 4.0

\section{REPOSITORY RECORD}

Rahimifard, Shahin, Elliot Woolley, D. Patrick Webb, Guillermo Garcia-Garcia, Jamie Stone, Aicha Jellil, Pedro Gimenez-Escalante, Sandeep Jagtap, and Hana Trollman. 2019. "Forging New Frontiers in Sustainable Food Manufacturing". figshare. https://hdl.handle.net/2134/24925. 


\title{
Forging New Frontiers in Sustainable Food Manufacturing
}

\author{
Shahin Rahimifard ${ }^{1}$, Elliot Woolley ${ }^{1}$, D. Patrick Webb ${ }^{1}$, Guillermo Garcia- \\ Garcia $^{1}$, Jamie Stone ${ }^{1}$, Aicha Jelliil ${ }^{1}$, Pedro Gimenez-Escalante ${ }^{1}$, Sandeep \\ Jagtap $^{1}$ and Hana Trollman ${ }^{1}$ \\ ${ }^{1}$ Centre for Sustainable Manufacturing and Recycling Technologies \\ Loughborough University, UK, s.rahimifard@lboro.ac.uk
}

\begin{abstract}
One of the most prominent challenges commonly acknowledged by modern manufacturing industries is 'how to produce more with fewer resources?' Nowhere is this more true than in the food sector due to the recent concerns regarding the long-term availability and security of food products. The unique attributes of food products such as the need for fresh perishable ingredients, health risks associated with inappropriate production environment, stringent storage and distributions requirements together with relatively short post-production shelf-life makes their preparation, production and supply considerably different to other manufactured goods. Furthermore, the impacts of climate change on our ability to produce food, the rapidly increasing global population, as well as changes in demand and dietary behaviours both within developed and developing countries urgently demands a need to change the way we grow, manufacture and consume our food products. This paper discusses a number of key research challenges facing modern food manufacturers, including improved productivity using fewer resources, valorisation of food waste, improving the resilience of food supply chains, localisation of food production, and utilisation of new sustainable sources of nutrition for provision of customised food products.
\end{abstract}

Keywords: Resource Efficient Food Manufacturing, Valorisation of Food Waste, Resilience in Food Supply, Provision of Customised Food Products.

\section{Introduction}

Global Food Supply Chains (GFSCs) are highly complex systems developed in response to modern consumer demands for trusted food products and services, and improved choice and quality at lower prices. GFSCs within the majority of developed countries and increasingly in emerging economies are often dominated by a small number of large retailers and their supply networks. These in turn have evolved around management paradigms focussed on cost

adfa, p. 1, 2011. 
minimisation and service optimisation based on models of 'Centralised Production' (determined by economies of scale and cheap labour) and 'Just in Time' approaches to eliminate non-value adding activities. Whilst such management systems have been well suited to times of stability, they are now vulnerable to volatility. A number of factors including global population growth (predicted to grow to around 9.7 billion by 2050), intensification of food production, varying cost and availability of fuel, and more crucially the impacts of climate change which is projected to exacerbate challenges from drought, flooding, pests, diseases and weeds all increase volatility in the food sector [1][2]. In addition, a wide range of factors such as the general global transition towards increasingly meat and dairy based diets, ageing populations and concerns about the health impacts of food, as well as modern social complexities associated with increased urbanisation, highlight an urgent need to improve the long-term sustainability of food manufacturing, as depicted in Fig. 1.

A misconception is often that 'Global Food Security' must be about growing more crops and increasing global production output. However, improving distribution, increasing productivity, and reducing waste though a range of initiatives such as enhancing food supply, better network planning of outlets and distribution to maximise efficiency and improve resilience, utilisation of new materials and biomaterial processing, multiple use of crops/waste streams and novel processes to minimise water and energy requirements, are all equally important considerations upon which the future of the food sector must be founded.

The initial section of this paper provides an overview of challenges and a number of key research questions in sustainable food manufacturing, and the latter sections of the paper briefly describe a number of relevant contemporary research areas in pursuit of improving the resource efficiency, resilience and long-term security of GFSCs.

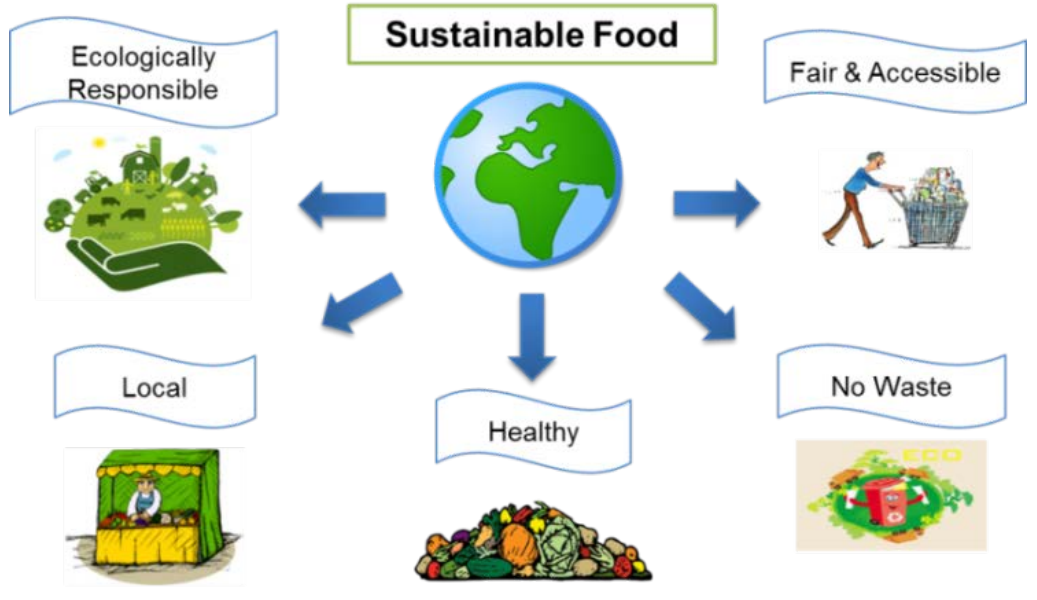

Fig. 1. New Frontiers in Sustainable Food Manufacturing 


\section{Forging New Frontiers in Sustainable Food Manufacturing}

It is argued that future food research activities must focus not only on identifying new sources of materials but also reducing the demand on existing resources through simultaneous considerations of innovation and development initiatives targeted at food products, processing methods, and supply networks. In this context, some of the key research questions are:

- How do we improve the efficiency of food production processes (e.g. through improved automation and smart technologies) to consume fewer resources (materials, energy and water)?

- How can we eliminate the production and post-production waste caused by inefficient supply and manufacturing activities and /or relationships?

- How do we use material currently discarded as waste (e.g. biomass) as a new source of raw material in food production?

- How do we measure, monitor and ultimately minimise the energy and water consumption per unit across the entire supply chain of food products?

- How can we prepare customised food products specifically tailored to the needs of consumers with restricted choice (e.g. coeliac disease)?

- How can supply chain resilience towards the range of aforementioned global challenges and volatility be better modelled and enhanced?

The remaining sections of this paper highlight a range of multi-disciplinary interlinked research areas in support of sustainable food manufacturing, as depicted in Fig. 2.

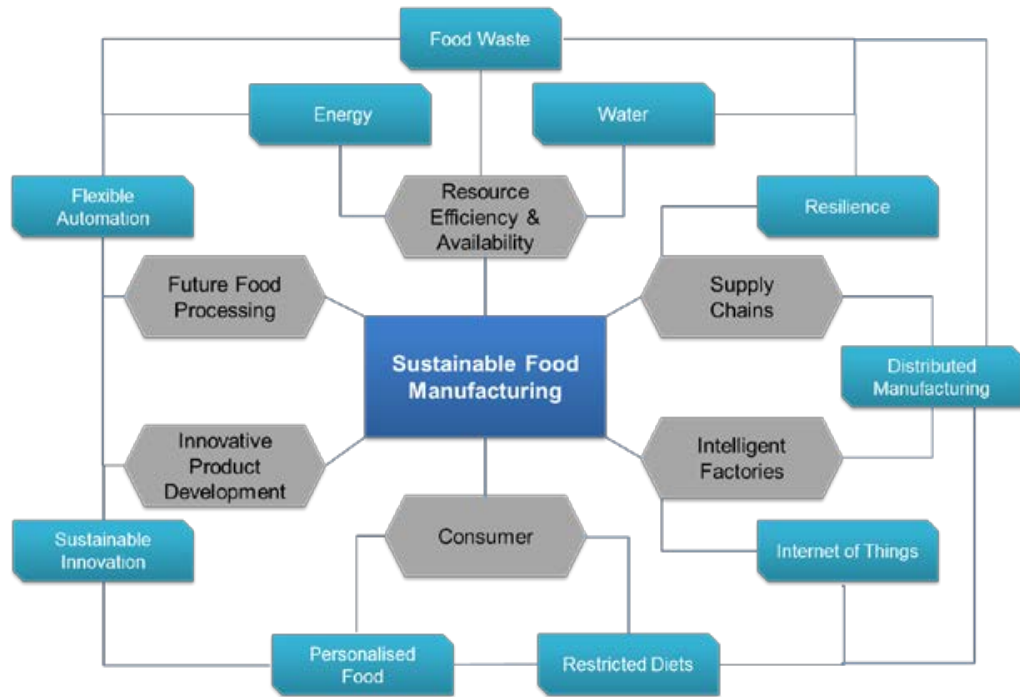

Fig. 2. Key Future Research Challenges in Sustainable Food Manufacturing 


\section{Valorisation of Food Waste}

Food manufacturing is a complex process that at present is in the main linear - rather than based on circular - thinking. Globally, a staggering 1.3 billion tonnes of edible food is wasted per year both in developing and developed areas of the world [3]. Food waste has a dual negative environmental impact, namely undue pressure on natural resources and ecosystem services as well as pollution caused through food discards. It also entails a significant economic cost at all levels of the food supply chain, from farmers and food manufacturers to retailers and consumers. Currently, most common strategies for dealing with food waste are animal feeding, anaerobic digestion, composting, waste to energy (such as incineration), landspreading, and least preferably open burning (without energy recovery) and landfilling. Fig. 3 shows the Food Waste Hierarchy, with the most sustainable waste management solutions at the top and the least sustainable options at the bottom.

Food waste is unique as a bioresource: it is rich in ingredients which may be re-used for nutritional, functional and textural properties. Hence, a deeper understanding of the characteristics and properties of food waste is necessary to identify opportunities where these under-utilised resources can be valorised. Preferably, food waste should be used to create new food products, by extracting and separating its valuable ingredients. The High Level Panel of Experts on Food Security and Nutrition from the UN 'Food and Agricultural Organisation' (FAO) concluded that valorisation approaches for food waste and by-products streams can be regarded as a key solution in global food security [4].

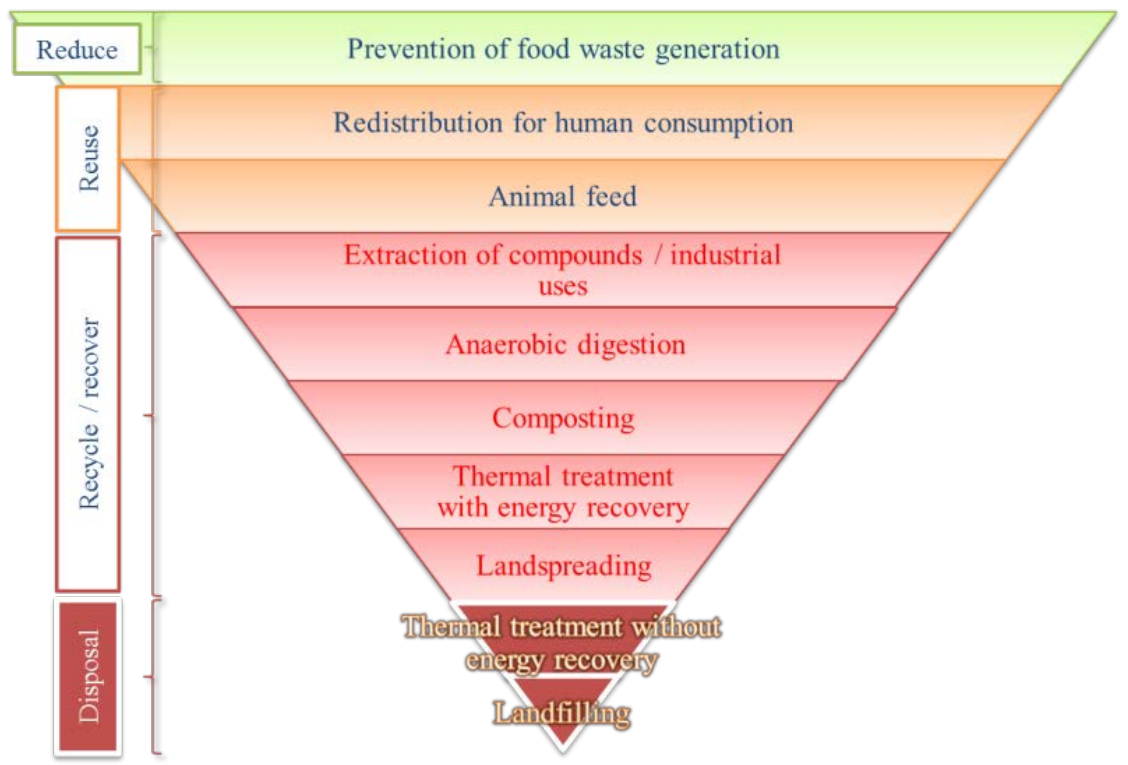

Fig. 3. The Food Waste Hierarchy [5] 


\section{Influencing Consumer Behaviour to Reduce Food Waste}

Consumer food waste is a global issue where one third of food produced never gets consumed, revealing a need to promote more sustainable consumption. Interestingly, in the developing countries, $40 \%$ of food waste is created in the field and during initial processing, whereas in developed countries, $40 \%$ of food waste is generated at the retail and consumption stages [6]. Studies have demonstrated that consumer food waste should not be conceptualised as solely a behavioural problem but rather as a symptom of an unsustainable food system that overproduces, oversupplies, and encourages consumerism [7][8]. Manufacturers and retailers can play a crucial role in minimising consumer food waste, due to the strategic position they hold in controlling the flow of goods from producers to consumers. It is proposed that bridging the gap between food production and consumption can be achieved through a range of considerations including acquiring a deeper understanding of consumers' needs and demands, incorporating this understanding in various food production and retail activities, and using new advances in information technology to communicate more effectively with food consumers.

\section{Energy Management in Food Manufacturing}

The food industry is one of the largest users of energy in the world and therefore has a fundamental reliance on security of energy supply. There is some variation in energy demand between countries - those with more developed industrial systems tend to produce more highly processed foods and make them available all year round. In these countries, out-of-season agriculture, heating and drying of foodstuffs as well as transportation and storage of goods lead to large embodied energy within final food products. Therefore, the food manufacturing industry urgently needs to become resilient to changes in the energy supply grid [9]. This has been recognised and in some countries specific targets have been set; for example, in the UK the Courtauld Commitment demands a $20 \%$ reduction in greenhouse gas intensity of food and drink consumed by 2025 [10].

There are, fortunately, some major opportunities for improved energy resilience across food supply chains, which include better understanding of energy consumption in factories requiring more intelligent metering and analysis to identify energy inefficiencies, new technologies and application of technologies for food processing (e.g. microwave and infrared heating and drying), energy recovery from both process and facility levels, and finally incorporation of renewable energy technologies into food supply networks. 


\section{Improving Water Sustainability in Food Manufacturing}

Availability and sustainable management of scarce freshwater resources is a well-recognised priority in the food sector [11]. A major barrier to effective monitoring and control of water consumption in food processing is lack of realtime and process-specific water content data [12]. Currently available data typically comes from periodic sampling conducted at the main outfall of an industrial plant, and sent to a laboratory for analysis to check for discharge consent compliance. From the point of view of tackling the fundamentals of water and effluent reduction, this approach is inadequate due to the significant lag time between generation of effluent and receipt of analysis results, and the fact that samples are the aggregate output of multiple processes in the production chain, which makes it difficult to attribute results to specific process steps or plant operational conditions. To address these shortcomings, there is an urgent need for real-time capable instrumentation for continuous in-plant characterisation of individual water using processes and of the effluent load of the water streams they produce, as depicted in Fig. 4. Such instrumentation should be composed of two elements - a system for assessing and monitoring the contribution to water waste arising from cleaning processes [13], and another for characterising variations in water effluent magnitude and types [14]. These instrumentations can also be applied directly for real-time control of water using food processes to improve water sustainability through reuse and in-plant recycling of waste water.

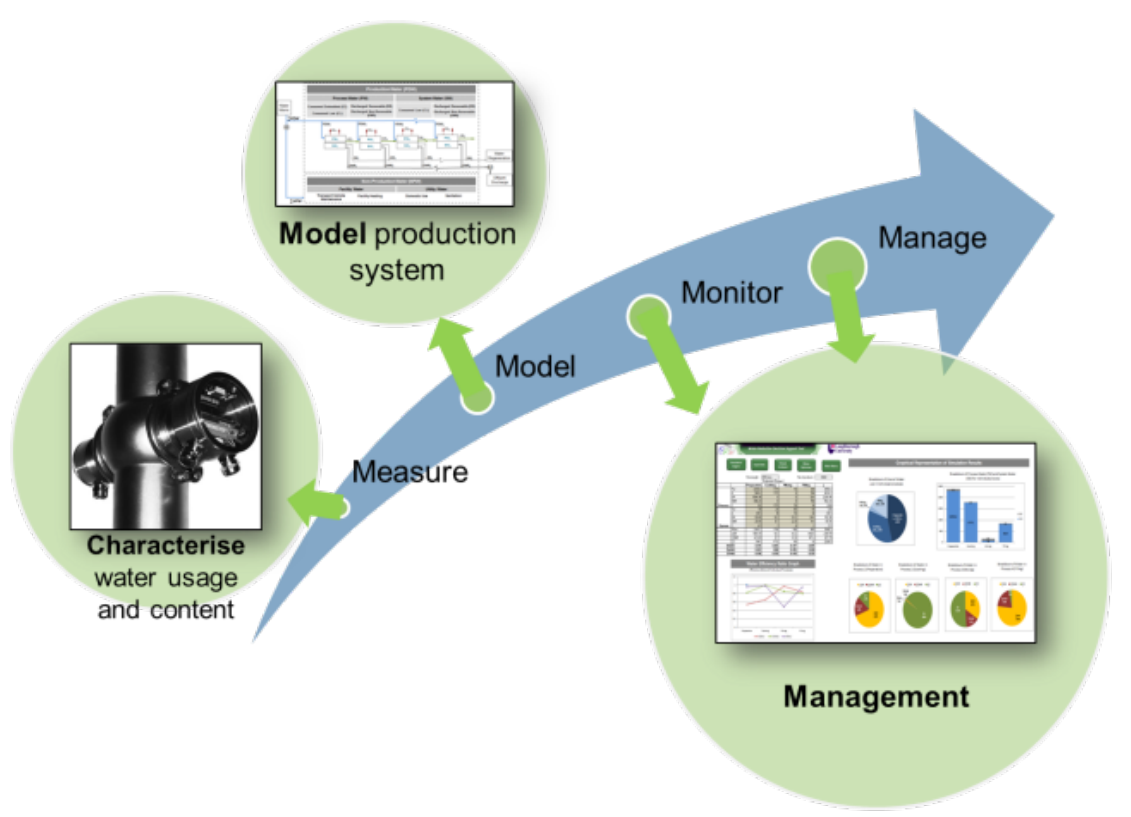

Fig. 4. : Real-time Monitoring and Control of Water Consumption in Food Manufacturing 


\section{Customised Food Products for Consumers with Restricted Choices}

Food product innovation is increasingly used to enhance people's lifestyles while reducing the negative impact of manufacturing [15]. These innovations could include considerations for intelligent food packaging design that helps to increase the shelf life of a fresh product and minimizes post-production waste [16], use of alternative protein sources for nutritionally optimised foods, and product reformulation based on seasonal and locally available ingredients.

In addition, Non Communicable Diseases (NCDs) are increasingly imposing a significant burden on public health. Most cases of obesity, cardiovascular disease and type II diabetes are preventable as these diseases are directly linked to unhealthy dietary habits and sedentary lifestyles [17]. On the other hand, life expectancy is on the rise in the majority of developed countries, for example senior citizens are expected to constitute $23 \%$ of the UK population in 2035 [18]. Despite these facts, current efforts to provide the market with healthy and customised industrial foods are very limited. This highlights an urgent need for investigating various options for provision of customised and personalised food products specially tailored to the specific requirements of consumers with restricted food choices.

\section{Use of Robots to Provide Flexible Automation in Food Manufacturing}

The food industry is continuously being challenges to meet the demands for short-term inclinations to certain products. Many manufacturers are resorting to producing a wider variety of products in smaller batches that are suitable for a number of individual tastes. However, they face the issue of having rigid automated processes that are often designed for mass production of a small number of product types, thus limiting their flexibility in production. In addition, the substantial investment required in implementing large scale automation has often been a prohibiting factor for Small and Medium Enterprises (SMEs) to adopt automated processes within their production line. In this context, the low-cost flexible automation provided through use of robots would be an ideal solution for SMEs to improve their flexibility, productivity and product quality [19]. Furthermore, utilisation of robotic systems would enable larger manufacturers to quickly respond to market and customer changes by making the most of trends, seasonal products and frequently changing product designs, all while reducing production costs and improving quality.

Currently, use of robots in food production is mainly focused on finishing processes (e.g. packaging and palletising), but there is an inherent need for such flexible automation in processes higher up the production line to increase productivity [20]. Developing robots for food handling and processing is often challenged by irregularity in shape and non-rigidity of foodstuffs, which make them easily deformable. 


\section{Distributed and Localised Food Manufacturing}

Traditional business models focusing on the centralisation and large scale production of food products are increasingly being challenged due to emerging demand for authentic local products and consumer concerns for the sustainability of food systems. The need for a shift towards more distributed localised food manufacturing systems (see Fig. 5) has been highlighted by a range of factors such as changes in transport and labour costs, high volumes of food waste associated with large supply chains, the availability and access to materials, energy and water, and uncertainties regarding the long-term resilience of complex global food systems [21].

The concept of distributed localised manufacturing has been identified as an emerging organisational theory that can support the food industry in its upcoming challenges [22]. Such distributed localised production of food is expected to support the provision of customised/personalised food products coordinated with dietary requirements, to create more agile and shorter food supply chains, and to minimise environmental impacts and costs associated with food transportation and storage.

\section{Resilience in Global Food Supply Chains}

Contemporary food supply chains are able to offer a huge and previously unimaginable variety of safe and competitively priced food products. A number of changes over recent decades have enabled this, including 'globalisation' of supply chain networks and 'leaning' of food processing and provision so as to remove all non-value adding features. The benefits of such an approach are substantial, but so too is the risk, when the non-value adding features which are often eliminated include traditional buffers against disruption.

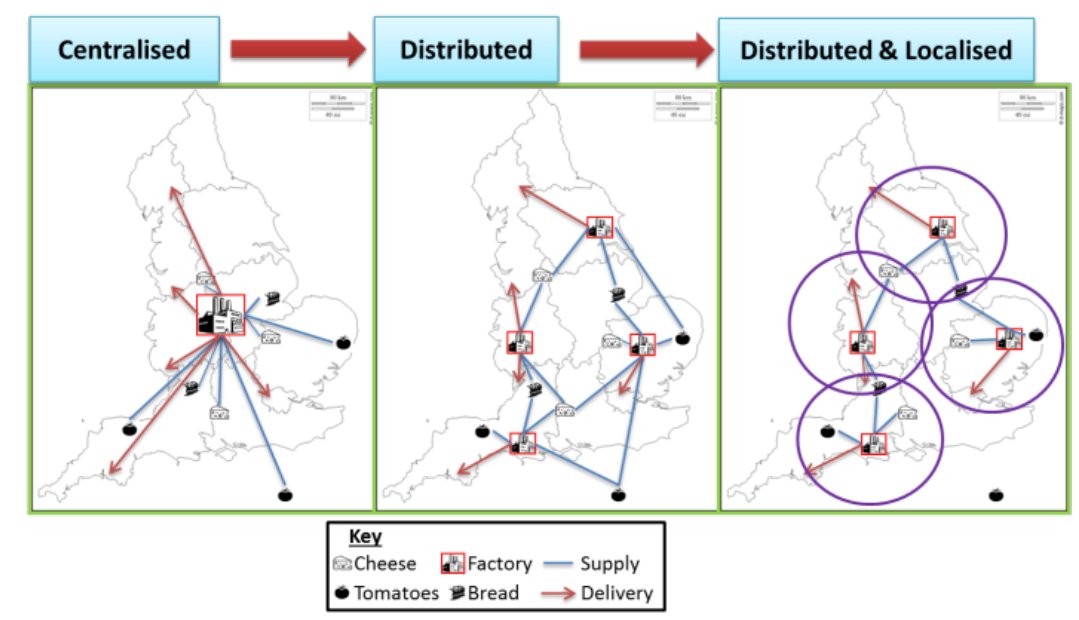

Fig. 5. Distributed and Localised Food Manufacturing 
Recently, we have seen vegetable shortages in Europe as a result of poor weather and we can expect the risk of further such disruptions to grow in light of global stressors such as climate change, population growth and dietary transition. Yet resilience is something of a buzzword, used interchangeably with related themes such as sustainability. Contrary to popular belief, resilience does not simply concern resisting a disruption. Rather, it is the ability to adequately anticipate potential disruptions, to react in such a way that disruption to standard operations is minimised and to learn and adapt in response to the disturbance, even if this requires fundamental changes to operational models [23]. This 'resilience cycle' is depicted in Fig. 6.

Understanding resilience in this way should allow much more refined matching of a given stakeholder's management options (known as capabilities) to the specific vulnerabilities facing them [24]. However, there is a real need for further empirical research across the food supply chain (i.e. ranging from primary production to retail) to identify specific food sector capabilities and vulnerabilities, and the linkages and interactions between them.

\section{Utilisation of 'Internet of Things' to Improve Food Resource Efficiency}

The food sector is increasingly under pressure to improve its resource efficiency [25]. In order to achieve this, it is vital for the food supply chain actors to share and exchange knowledge and information on resource use and availability in a timely manner. The traditional methods of physically monitoring and managing resources are labour intensive and complex, and are often time consuming and costly.

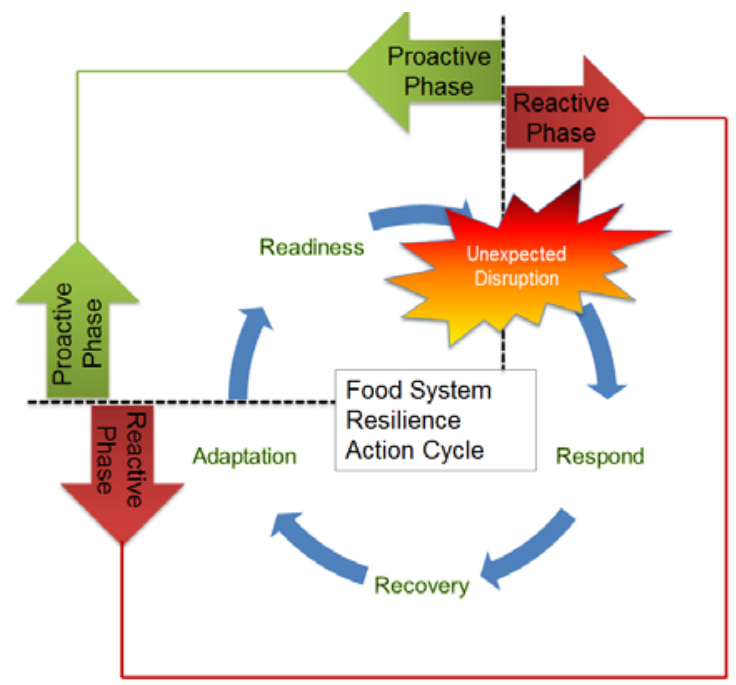

Fig. 6. The Different Phases of the Resilience Cycle in Food Manufacturing 
The technology and tools associated with the concept of the Internet of Things (IOT) are capable of supporting numerous tasks in real-time such as tracking, locating, monitoring, measuring, analysing, planning and managing, and enhancing efficiency and transparency within food supply chains [26], as depicted in Fig. 7.

This highlights the significant potential offered through the latest IoT advancements to support innovative approaches based on an automated realtime systems for monitoring and analysing the resource usage across entire food production and supply. Such timely management and provision of appropriate knowledge and information could potentially result in more effective strategic planning and better decision making in support of resource efficient and sustainable food supply chains.

\section{Concluding Remarks}

The food manufacturing industry seeks continuous improvements in most of its activities in order to not only increase profitability, but also to provide consumers with better products that can satisfy their changing needs. Competitive measures implemented by food manufacturers have focussed specifically on three key performance indicators: productivity, quality and innovation. By developing strategies which could improve any of these three business indicators, food manufacturers have been able to grow and create more valuable food products for consumers.

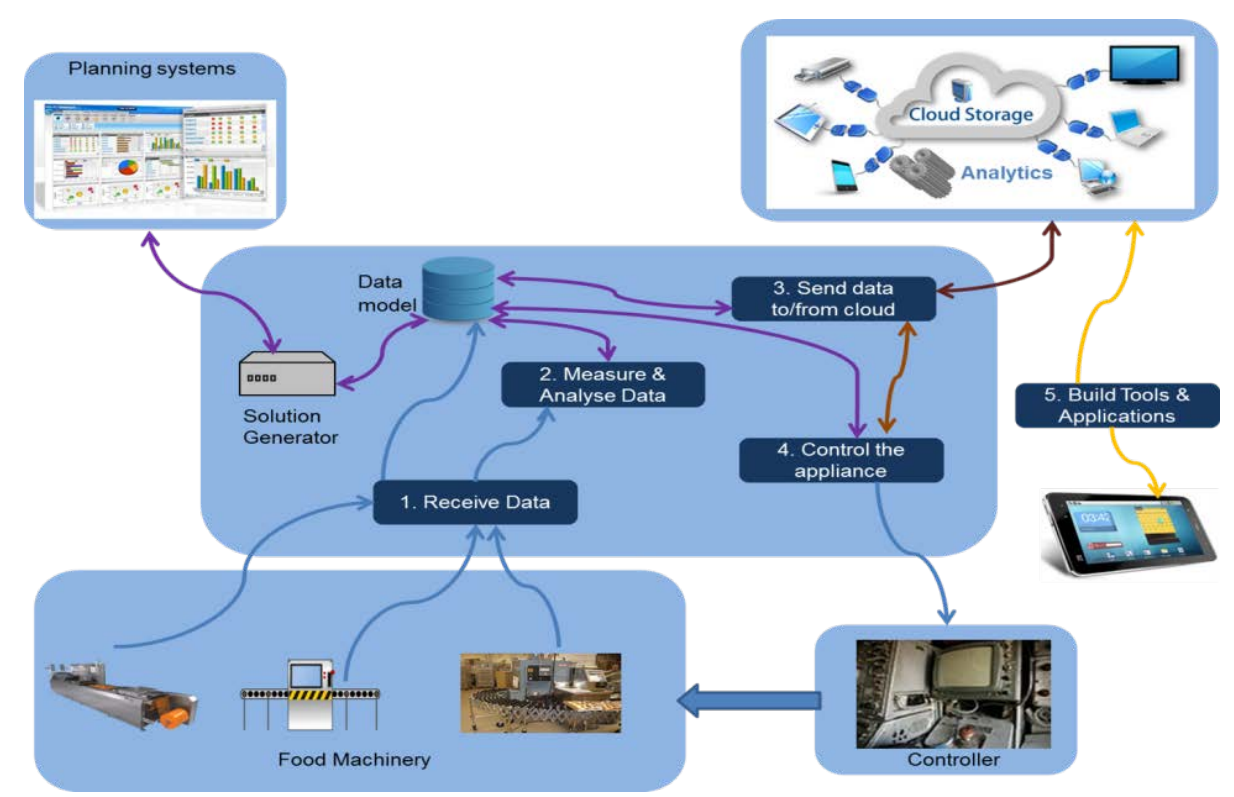

Fig. 7. Use of Internet of Things (IoT) Concepts to Enhance Resource Efficiency within Food Supply Chains 
However, rising environmental concerns and associated pressure from governments and consumers are now increasingly forcing the food sector to strive to improve the sustainability of their products, production processes, supply chains and business strategies. Consequently, innovative approaches that can provide the industry with meaningful and significant improvements are being explored due to the ever-increasing need to adapt and change in order to remain competitive. In addition, due to the unique attributes of food products and their impact on the health and wellbeing of consumers, these improvements must go beyond environmentally conscious manufacturing and should also contribute to the shared prosperity between business and community, and between human society and natural ecosystems. The achievement of such goals clearly necessitates a complex and significant transition, which not only requires "smart" strategies to safeguard the future prosperity of food manufacturers, but also a collective and continuous drive from businesses, communities and policy makers towards long-term global food security.

\section{References}

1. United Nations Department for Economic and Social Affairs, 2015, World Population Prospects, Available at: https://esa.un.org/unpd/wpp/, [Accessed 23/02/2017].

2. Allison, E.H., Perry. A.L., Badjeck, M.C., Neil Adger, W., Brown, K., Conway, D., Halls, A.S., Pilling. G.M., \& Reynolds, J., 2009, Vulnerability of national economies to the impacts of climate change on fisheries, Fish and Fisheries. 10(2), 173-196.

3. FAO, 2011, Global food losses and food waste- Extent, causes and prevention, Available at: http://www.fao.org/docrep/014/mb060e/mb060e00.pdf, [Accessed 3/02/2017].

4. The High Level Panel of Experts on Food Security and Nutrition (HLPE), 2014, Food losses and waste in the context of sustainable food systems, Rome, Available at: http://www.fao.org/3/a-i3901e.pdf, [Accessed 23/02/2017].

5. Garcia-Garcia, G., Woolley, E., Rahimifard, S., Colwill, J., White, R., \& Needham, L., 2016, A Methodology for Sustainable Management of Food Waste, Waste and Biomass Valorization, doi:10.1007/s12649-016-9720-0.

6. FAO, 2016, Save food: global initiative on food loss and waste reduction, Available at: http://www.fao.org/save-food/resources/keyfindings/en/, [Accessed 23/02/2017].

7. Evans, D., 2011, Blaming the consumer - once again: the social and material contexts of everyday food waste practices in some English households, Critical Public Health, 21(4), 429-440.

8. Aschemann-Witzel, J., de Hooge, I., Amani, P., Bech-Larsen, T., \& Oostindjer, M., 2015, Consumer-related food waste: causes and potential for action, Sustainability, 7(6), 6457- 6477.

9. European Commission, 2015, Energy use in the food sector: state of play and op-

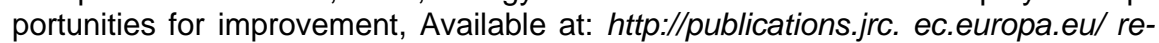
pository/bitstream/JRC96121/ldna27247enn.pdf, [Accessed 23/02/2017].

10. Waste \& Resources Action Programme (WRAP), 2017, Household Food Waste in the UK, Available at: http://www.wrap.org.uk/sites/files/wrap/Household_food_ waste_in_the_UK_2015_Report.pdf, [Accessed 23/02/2017]. 
11. Ölmez, H., \& Kretzschmar, U., 2009, Potential alternative disinfection methods for organic fresh-cut industry for minimizing water consumption and environmental impact, LWT - Food Science and Technology, 42 (3), 686-693.

12. Sachidananda, M., \& Rahimifard, S., 2012, Reduction of water consumption within manufacturing applications, Proceedings of the 19th CIRP Conference on Life Cycle Engineering, Berkeley - US, 455-460.

13. Simeone, A., Watson, N., Sterritt, I., \& Woolley, E., 2016, A multi-sensor approach for fouling level assessment in clean-in-place, Procedia CIRP, 55:134-139.

14. Sachidananda, M., Webb, D.P., \& Rahimifard, S., 2016, A concept of water usage efficiency to support water reduction in manufacturing industry, Sustainability, 8(12):1222

15. Bonzanini, M., Dutra De Barcellos, M. \& Marques Vieira, L., 2016, Why food companies go green? The determinant factors to adopt eco-innovations. British Food Journal, 118(6), $1317-1333$.

16. Verghese, K., Lewis, H. \& Lockrey, S., 2013, The role of packaging in minimising food waste in the supply chain of the future, Melbourne: RMIT University.

17. Pereira, M.A., Kartashov, A.L., Ebbeling, C.B., Van Horn, L., Slattery, M.L., Jacobs J.R., \& Ludwig, D.S., 2005, Fast-food habits, weight gain, and insulin resistance (the CARDIA study): 15-year prospective analysis. The Lancet, 365 (9453), 36-42.

18. UK Parliament, 2012, Population ageing: statistics, Available at: researchbriefings.files.parliament.uk/documents/SN03228/SN03228.pdf, [Accessed 20/1/2017].

19. Cederfeldt, M. \& Elgh, F., 2005, Design Automation in SMEs - Current State, Potential, and Requirements, $15^{\text {th }}$ International Conference on Engineering Design, 1507-1521.

20. Nayik, G. Ahmad, K.M., and Amir, G., 2015, Robotics and Food Technology: A Mini Review, Journal of Nutrition \& Food Sciences, 5 (4), 1-11.

21. Li, D., Wang, X., Chan, H.K., \& Manzini, R., 2014, Sustainable food supply chain management, International Journal of Production Economics, 152, 1-8.

22. Rauch, E., Dallasega, P., \& Matt, D.T., 2016, Sustainable production in emerging markets through Distributed Manufacturing Systems, Journal of Cleaner Production, 127-138.

23. Christopher M., \& Peck, H., 2004, Building the resilient supply chain. International Journal of Logistics Management, 15 (2), 1-4.

24. Hohenstein, N.O., Feisel, E., Hartmann, E., \& Giunipero, L., 2015, Research on the phenomenon of supply chain resilience: a systematic review and paths for further investigation, International Journal of Physical Distribution \& Logistics Management. 45 (1/2). 90-117.

25. Dawkins, E, Roelich, K, Barrett, J, \& Baiocchi, G., 2010, Securing the future - The role of resource efficiency, Banbury: WRAP, Available at: http://www.wrap.org.uk/ sites/files/wrap/Securing\%20the\%20future\%20The\%20role\%20of\%20resource\%2 Oefficiency.pdf, [Accessed 20/02/2017].

26. Xiaorong, Z., Honghui, F., Hongjin, Z., \& Hanyu, F., 2015, The Design of the Internet of Things Solution for Food Supply Chain. 5th International Conference on Education, Management, Information and Medicine, Shenyang - China, 314-318. 